Issues in Information Systems

Volume 18, Issue 4, pp. 124-134, 2017

\title{
ASYNCHRONOUS AND SYCNRHONOUS SESSIONS IN ONLINE COURSES: GRADUATE STUDENTS PERCEPTIONS
}

\author{
Zoroayka V. Sandoval, The University of Texas Rio Grande Valley \& Universidad Autonoma de Tamaulipas, \\ vicky.sandoval@gmail.com
}

\begin{abstract}
Asynchronous and synchronous courses are offered in higher education for students enrolled in online learning. Asynchronous courses are usually available anytime for students; synchronous sessions vary, such as the time they are offered, length, frequency, and content covered in the session. Preferences of graduate students regarding their online courses are explored. The courses analyzed in this study are project-based, fully available asynchronously, and voluntary synchronous sessions are offered by the instructor on a weekly basis. Since all the content of the course is available on the course site, it was found that graduate students prefer short voluntary live sessions, offered less frequently, where key points are addressed by the instructor. Recordings of the synchronous sessions were also preferred by students, since, due to time constraints, they are not able to attend to the synchronous meetings. This study analyzed perceptions of graduate students regarding their preferences of synchronous and asynchronous modalities in the courses they are enrolled. Some recommendations for designers and faculty teaching online courses are discussed at the end of the article.
\end{abstract}

Keywords: Asynchronous Learning, Synchronous Sessions, Fully Online Courses

\section{INTRODUCTION}

Students enrolled in online higher education courses receive instruction through different delivery modes. Usually, courses are delivered either in fully asynchronous or synchronous modes or a combination of both. One of the main characteristics of asynchronous delivery is that it "does not require the real-time participation of instructor and students," but interaction between them is given by the use of online communication tools, such as email, discussion forums, blogs, wikis, and video/audio recordings (Huang \& Hsiao, 2012, p. 15), and content material is completely available through the Learning Management System (LMS). Based on asynchronous course characteristics, students may ask questions using these tools, receive feedback within an established period of time, interact with course content anytime, and complete assignments at their own pace. For students with job and family responsibilities, the latter is a benefit they seek in order to succeed in higher education, although it implies having good organization and selfdiscipline skills (Hrastinski, 2008a).

On the other hand, synchronous delivery requires live interaction between instructor and students in established periods of time, using tools such as audio/video web conference software, chat, and telephone. In a synchronous class session, the instructor is able to present content, answer questions, and students participate live in the class. Park and Bonk reported that the benefits of the use of synchronous learning include "providing immediate feedback, encouraging the exchange of multiple perspectives, enhancing dynamic interactions among participants, strengthening social presence, and fostering the exchange of emotional supports and supplying verbal elements" (as cited in Martin \& Parker, 2014, p. 193), thus increasing students' sense of relatedness by having social interaction with peers and receiving immediate feedback from instructor (Giesbers, Rienties, Tempelaar \& Gijselaers, 2014). Making recordings of synchronous sessions have also been reported to be beneficial for students, since those who were not able to attend or need some clarification can later use the recording for self-review (Martin \& Parker, 2014).

A combination of synchronous and asynchronous forms of communication in online courses, where the course materials are fully available through the LMS and synchronous live sessions are offered to students, has been reported to increase students' performance, participation, and outcomes (Clark, Strudler \& Grove, 2015; Hrastinski, 2008b). 
Giesbers, Rienties, Tempelaar, and Gijselaers (2014) argue that a combination of synchronous and asynchronous communication enhances learner engagement and development, because "direct feedback and support of social processes may be best supported through synchronous discussion, while asynchronous discussion may best support the development of higher-level thinking skills" (p. 31). For instance, the primary form of communication between peers and instructor in asynchronous online courses is usually the discussion forum (Clark, Strudler \& Grove, 2015), where students use more academic language and take the time to elaborate on their posts (Oztok, Zingaro, Brett \& Hewitt, 2013). By including a synchronous session, and if the instructor creates the opportunity for interaction, students socialize with peers and get immediate feedback and guide from the instructor. Burns, Cunningham \& ForanMulcahy (2014) noted that the use of synchronous elements in online instruction is not the only way to generate dialogue and student-instructor connection, since asynchronous dialogue have comparable forms of positive communication of equal value. For example, even though instructors offer online office hours, where studentinstructor could hold a live session (synchronous), email (asynchronous) has found to be the predominant tool for communication with the instructor in online courses (Huang \& Hsiao, 2012).

Although a combination of delivery methods to improve instruction is suggested, online learning has limitations. Clark, Strudler, and Grove (2015) found that time constraints, as well as personal responsibilities, are the main limitations for students to invest time in online learning. Isolation, lack of interaction, lack of immediate feedback, and technological skills are also limitations (Willging \& Johnson, 2009; Burns, Cunningham \& Foran-Mulcahy, 2014; Huang \& Hsiao, 2012; Branon \& Essex, 2001). Course designers and faculty teaching online courses in higher education need to adopt best practices of online learning and be aware of the needs of students, in order to achieve learning outcomes while allowing them to accomplish personal and academic activities. As Burns, Cunningham, and Foran-Mulcahy (2014) suggested, online learning needs to be recreated instead of becoming only a replicate of faceto-face traditional courses.

Students participating in this study are graduate online learners taking courses with a combination of synchronous and asynchronous delivery modes. The aim of this study is to analyze students' preferences for the delivery of fully online courses. In the following sections, this article will present a description and main characteristics of the online courses studied in this research, as well as the results of the survey on the preferences of asynchronous or synchronous online courses. Based on students' perceptions and preferences regarding the delivery of online courses, recommendations for faculty will be discussed.

\section{DESCRIPTION AND CHARACTERISTICS OF THE ONLINE COURSES IN THIS STUDY}

The Educational Technology program at the university where this study was conducted, offers fully online courses at the undergraduate, masters, and doctoral levels. A team of faculty members in the program, design the courses with similar characteristics and components. For example, the courses include similar visual design (such as interface templates, and organization of the elements in the LMS), course components (such as videos, tutorials, projects' instructions and deliverables, and external resources) and requirements (such as participation in discussion boards, and working on group and/or individual projects).

All the Educational Technology courses are project-based, which allows students to complete course assignments and work in the projects at their own pace, without the requirement of attending classes. Usually in the courses, the students are required to complete 2 to 4 (individual and/or group) projects, and participate weekly on forums to discuss courserelated topics and share ideas with classmates.

The faculty have paid close attention to details of the course design, in order to incorporate usability guidelines and prevent learners' frustration when interacting, navigating, and participating in the course. Previous students' perceptions of the course design have been collected at the department level, and the results showed a satisfactory level of usability, which means that students can easily interact and get benefits from the course if taught asynchronously.

The courses are delivered fully online with a noticeable difference between undergraduate and graduate courses: both are asynchronous but most of the graduate courses offer voluntary scheduled synchronous sessions with the instructor. 


\section{Issues in Information Systems \\ Volume 18, Issue 4, pp. 124-134, 2017}

In the undergraduate courses, the instructor is present throughout the course by participating in discussion forums, answering students' questions via email, video conference, or telephone, and posting frequently announcements and reminders in the course. In the graduate courses, the instructor participates in the same way as the undergraduate courses but also provides voluntary synchronous sessions through Blackboard Collaborate. For the purpose of this study, participants are only masters and doctoral students who are offered non-mandatory synchronous sessions.

Voluntary synchronous sessions for graduate students are offered weekly and scheduled in the evenings (between 7 and 9 p.m.). This time frame is considered to be more suitable for learners since most of them are working full-time. On average, the sessions are about one-hour in duration, and since they are completely voluntary, students are encouraged, but not required to attend the sessions and participate.

In the synchronous sessions, the instructor offers diverse information to complement the information already included in the course sections (i.e. syllabus, projects, course materials), and students attending the sessions are able to discuss course assignments with the instructor and classmates. For example, in a synchronous session meeting, a combination of the following can be found:

- The instructor summarizes the weekly readings and emphasizes key points of the topics

- The instructor elaborates in projects' requirements and deliverables

- Students ask questions and receive immediate feedback from the instructor

- Students present their individual or group work

- Students share their projects' progress and get feedback and ideas from the instructor and classmates

- Instructor and students share tools and technologies that are useful to complete projects

Since the synchronous sessions are not mandatory, the meetings are recorded and archived in the course's site for future reference. As they are added to the course, the recordings are always available to students throughout the semester.

\section{THE STUDY}

Since all the graduate online Educational Technology courses are asynchronous with the core courses having a voluntary synchronous session, the purpose of this study was to determine and analyze students' perceptions of the asynchronous and synchronous delivery modes of the courses in order to identify their preferences. Findings will help faculty determine whether to expand or reduce the use of synchronous sessions to better meet students' needs.

Participants in this study were graduate students. At the time of their participation in the survey, participants were enrolled in one or more graduate online Educational Technology courses, being either at the Masters in Educational Technology or at the Doctorate in Curriculum and Instruction with specialization in Educational Technology. Using a blog, where students have active participation during the semester, the team of faculty designing and teaching online courses in the program launched a survey. The survey was hosted on a free-online survey service, and embedded in the blog's post, to facilitate participants' contributions. Additionally, an open-ended question was launched in the same post, asking students to share their perceptions of the delivery modes of the Educational Technology courses (synchronous and asynchronous), and providing suggestions for improvement. Students from the 9 graduate online Educational Technology courses offered in the Spring 2017 semester at the university participated in the survey, collecting a total of 44 responses in a one-week time period. The survey was composed of 5 multiple-choice questions with a single-option response, 6 Likert-scale questions, and 1 open-ended question, for a total of 12 questions.

\section{RESULTS}

In this section, the results of the data analyzed are presented. The first question aimed to explore the level of education in which participants were enrolled, asking if they were either masters or doctoral students. Results of Question 1 (Q1), revealed that $75 \%$ of the participants were enrolled at the master's level $(n=33)$ and $25 \%$ at the doctoral level $(\mathrm{n}=11)$, as shown in Figure 1. 


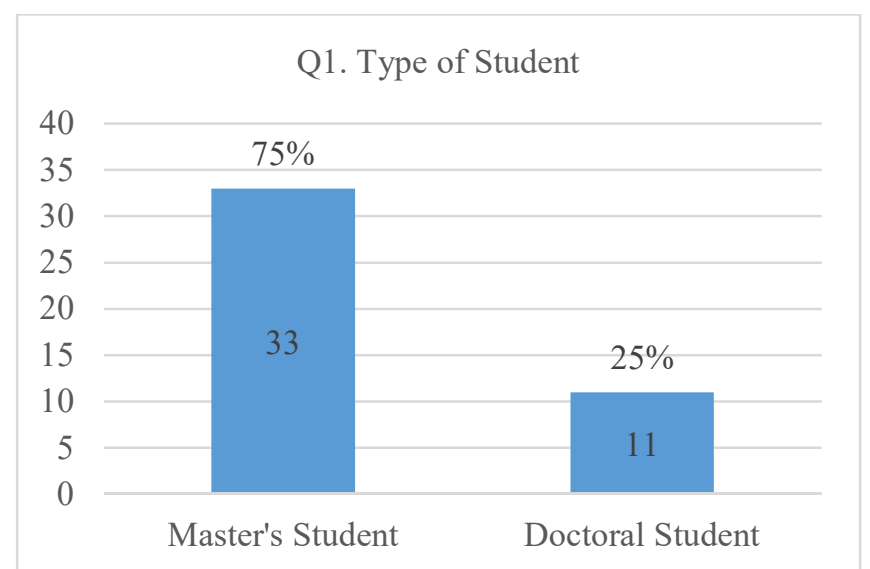

Figure 1. Survey Responses to the Type of Student $(n=44)$

Question 2 (Q2) asked participants the frequency in which they attend the synchronous sessions in the online course they were participating in the semester of the survey, and $30 \%$ of the participants $(n=13)$ reported that they attend the sessions sometimes. However, as shown in Figure 2, $48 \%$ of the participants ( $23 \%$ and $25 \%$ respectively) indicated that they attend the sessions Always $(\mathrm{n}=10)$ or Very Often $(\mathrm{n}=11)$, which indicates a frequent participation in the synchronous sessions. The rest of the participants Rarely $(\mathrm{n}=6)$ or Never $(\mathrm{n}=4)$ attend.

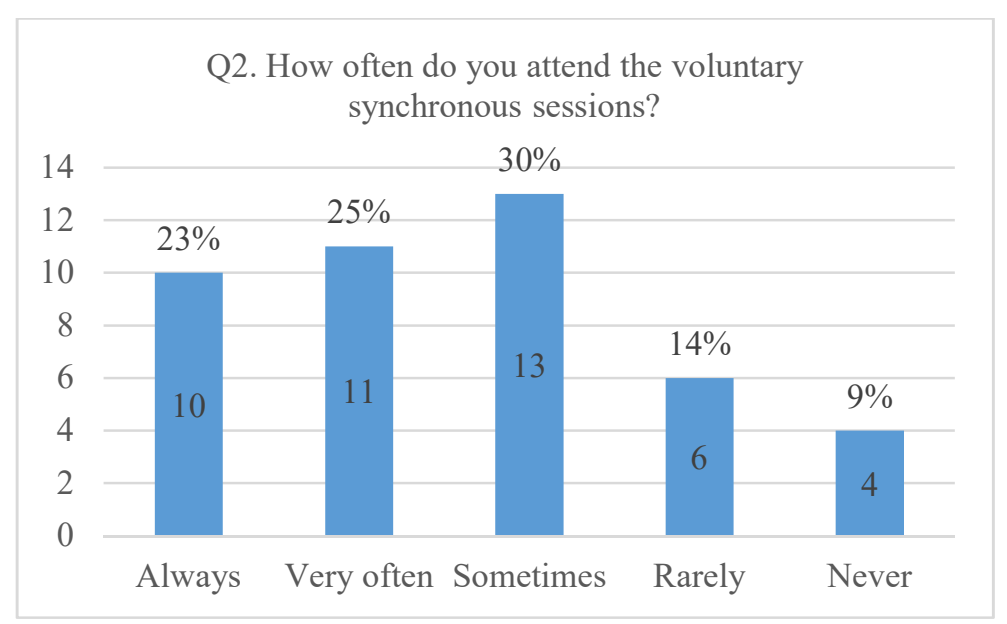

Figure 2. Survey Responses to the Attendance Frequency $(n=44)$

Despite the frequent participation in the synchronous sessions reported in Q2, the survey revealed in Question 3 that $39 \%$ of the participants $(n=17)$ prefer that synchronous sessions be offered only when they are requested or needed.

As shown in Figure 3, 30\% would like the sessions once a week $(n=13)$, and $18 \%$ twice a month $(n=8)$. Although the responses were anonymous, it is interesting that in Q3, 48\% of the participants would prefer the sessions with the same frequency they are being offered at the time this study was conducted (every one or two weeks), similarly to the same percentage (48\%) of participants reporting in Q2 a frequent participation in the sessions. 


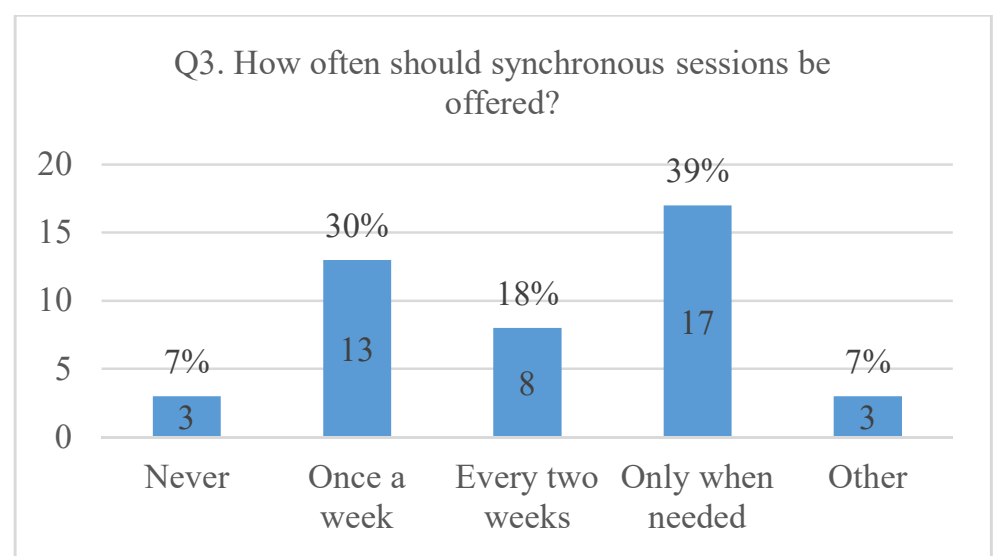

Figure 3. Survey Responses to the Preferred Frequency of the Sessions $(n=44)$

Only 3 participants (7\%) indicated that synchronous sessions should never be offered in the course. From the rest of the participants, more sporadic sessions are preferred. For example, one participant suggested the following:

Sessions should be offered 3 times: first, at the beginning of the semester to personalize and answer questions in real time; second, at mid-term to check in and offer feedback and answer questions; and third, at the end to wrap up and to clear up misconceptions.

When exploring the reason why participants have not been able to attend a synchronous session (Q4), $68 \%$ of them reported to had some other activities, either personal or work related, at the time the session was being held, while 2 participants (5\%) have forgotten to attend and 1 participant had another class scheduled at the same day and time than the synchronous session in the Educational Technology course. From the $23 \%$ of participants in Q2 reporting full participation in the sessions, this time only $18 \%$ responded that have always attended the sessions (see Figure 4).

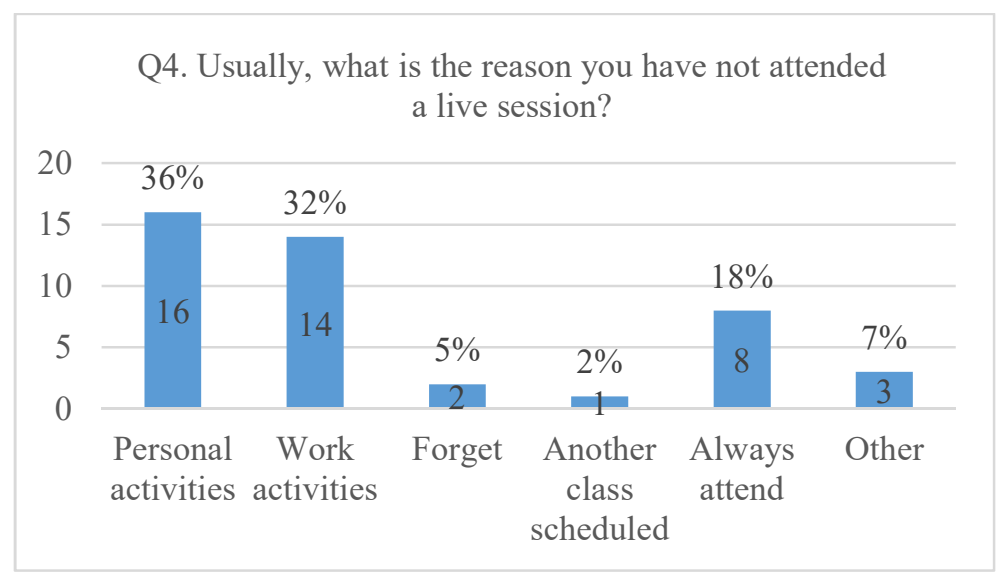

Figure 4. Survey Responses to the Reasons of not Attending a Session $(n=44)$

The other participants (7\%) indicated not attending a session because of diverse reasons, such as technical problems, not feeling comfortable in the session, or as one participant expressed:

Most of the sessions have been tremendously boring and wasted time.

Since an important time-frame section of the synchronous sessions is related to the discussion of the projects of the course (for example, elaborating in projects' deliverables, asking questions, and getting feedback), question 5 (Q5) explores the preferences of participants regarding the preferred way(s) to gather useful information to complete projects (Figure 5). The majority of the participants (43\%) indicated that they prefer referring only to the written 
instructions offered on each project's page, which means no interaction or communication with others. However, the other participants indicated a preference of having contact or interaction through different means. For example, $25 \%$ $(n=11)$ of the participants indicated a preference of having a synchronous session, either with the instructor and classmates $(n=9)$ or individually with the instructor $(n=2)$, and $11 \%(n=5)$ indicated preference for an asynchronous contact mode (email the instructor or contact classmates). From the rest of the participants, $18 \%(\mathrm{n}=8)$ responded that a combination of all the previous ways is what they prefer, and only 1 participant $(2 \%)$ reported to prefer the informative recorded session without students' interaction.

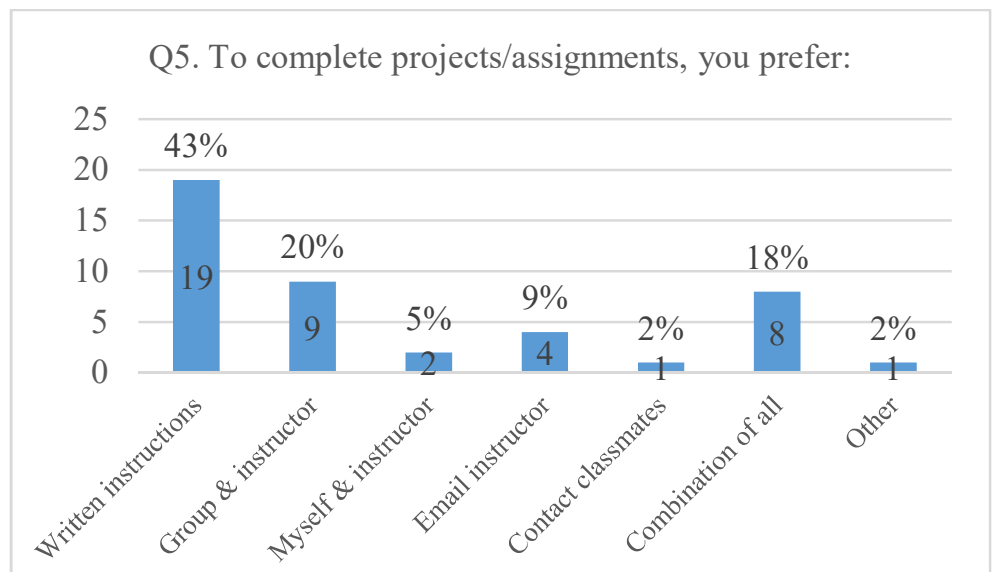

Figure 5. Survey Responses to the Type of Interaction Preferred to Complete Projects $(n=44)$

On the 5-point Likert-scale questions (Q6 - Q11), participants were asked to indicate to what extent they agreed with each of the statements shown in Table 1.

Table 1. Survey Responses by Question $(n=44)$

\begin{tabular}{|c|c|c|c|c|c|}
\hline Survey Item & $\begin{array}{l}\text { Strongly } \\
\text { Agree }\end{array}$ & Agree & Undecided & Disagree & $\begin{array}{l}\text { Strongly } \\
\text { Disagree }\end{array}$ \\
\hline \multirow{2}{*}{$\begin{array}{l}\text { Q6. I prefer an online course with synchronous } \\
\text { sessions. }\end{array}$} & $32 \%$ & $25 \%$ & $11 \%$ & $23 \%$ & $9 \%$ \\
\hline & 14 & 11 & 5 & 10 & 4 \\
\hline \multirow{2}{*}{$\begin{array}{l}\text { Q7. When I have attended a synchronous session, I } \\
\text { found it useful. }\end{array}$} & $32 \%$ & $36 \%$ & $23 \%$ & $7 \%$ & $2 \%$ \\
\hline & 14 & 16 & 10 & 3 & 1 \\
\hline \multirow{2}{*}{$\begin{array}{l}\text { Q8. Synchronous sessions increase the instructor's } \\
\text { presence in the course. }\end{array}$} & $45 \%$ & $32 \%$ & $11 \%$ & $9 \%$ & $2 \%$ \\
\hline & 20 & 14 & 5 & 4 & 1 \\
\hline \multirow{2}{*}{$\begin{array}{l}\text { Q9. Synchronous sessions allow me to collaborate } \\
\text { with and get to know my classmates. }\end{array}$} & $23 \%$ & $45 \%$ & $16 \%$ & $14 \%$ & $2 \%$ \\
\hline & 10 & 20 & 7 & 6 & 1 \\
\hline \multirow{2}{*}{$\begin{array}{l}\text { Q10. I would make time to attend if the sessions } \\
\text { were mandatory. }\end{array}$} & $30 \%$ & $36 \%$ & $23 \%$ & $9 \%$ & $2 \%$ \\
\hline & 13 & 16 & 10 & 4 & 1 \\
\hline \multirow{2}{*}{$\begin{array}{l}\text { Q11. If I wasn't able to attend a synchronous } \\
\text { session, I watch the recording. }\end{array}$} & $48 \%$ & $41 \%$ & $2 \%$ & $9 \%$ & - \\
\hline & 21 & 18 & 1 & 4 & - \\
\hline
\end{tabular}

When asked if they preferred online courses with synchronous sessions (Q6), the majority $(57 \%, \mathrm{n}=25)$ of the participants responded Strongly Agree/Agree, while 32\% $(\mathrm{n}=14)$ reported some level of disagreement (Disagree/Strongly Disagree). These results reveal that almost one-third of the population in this study were in favor of fully asynchronous online courses, as it is reflected in the following comments from the open-ended question: 


\section{Issues in Information Systems}

Volume 18, Issue 4, pp. 124-134, 2017

The asynchronous classes are significantly more convenient and to me represent the most important distinguishing feature of these classes. I see absolutely no point in synchronous modality at the time when any question can be posted/replied to on the class's wiki.

I actually prefer asynchronous classes because they allow me to learn the material on my own time and take away the anxiety of being on the spot to answer a question.

On the contrary, for diverse reasons, such as immediate feedback and communication, more than half preferred having synchronous sessions. For example, in the open-ended question, a participant wrote:

I find comfort in meeting with classmates and the instructor. This allows me to get real time answers to my questions and learn from what my classmates contribute to the session. Second, I always have questions and like clarification on instructions and synchronous lessons feed my need for immediate gratification. Third, these sessions answer a lot of the questions that I already have.

A highly positive response regarding the usefulness of synchronous sessions in online courses (Q7) was manifested by participants, as indicated by the $68 \%(\mathrm{n}=30)$ who responded Strongly Agree/Agree. Although $23 \%(\mathrm{n}=10)$ of the participants were undecided, only $9 \%(\mathrm{n}=4)$ did not find a synchronous session useful (Disagree/Strongly Disagree). Interestingly, even that fully asynchronous online courses were preferred in Q6 by 32\% of the participants, Q7 responses revealed that synchronous sessions were considered somehow useful by these participants because only $9 \%$ disagreed.

The survey results also revealed that $77 \%(\mathrm{n}=34)$ of the participants consider that synchronous sessions increase the instructor's presence in the course $(\mathrm{Q} 8)$, while only $11 \%(\mathrm{n}=5)$ disagreed or strongly disagreed with this statement. Similarly, 68\% ( $\mathrm{n}=30)$ indicated (Strongly Agree/Agree) that the sessions allowed them to collaborate with and get to know classmates $(\mathrm{Q} 9)$, and only $16 \%(\mathrm{n}=7)$ disagreed or strongly disagreed. The following comments are samples of what participants expressed in the open-ended question regarding instructor's presence and collaboration:

By having voluntary synchronous sessions we are able to be in contact with the professor and open the lines of communication.

When I have had synchronous sessions, I am able to feel more connected to my classmates and professor. I feel like we complete the course together on a deeper level.

Since synchronous sessions are not mandatory for the population in this survey, and attendance to the sessions varies as shown in Figure 2, Question 10 explored their level of agreement regarding making time to attend sessions if they were mandatory. A total of 29 participants (66\%) either Strongly Agree or Agree with this statement, while only 5 participants $(11 \%)$ reported disagreement, and the rest were undecided $(23 \%, \mathrm{n}=10)$. Although the majority agreed on making time to attend sessions if they were mandatory, some participants expressed hesitation, noting:

If they were required I sometimes had to burn my own Comptime or vacation time to attend the classroom meetings, sometimes with no benefit to my learning at all.

When I have had mandatory meetings it really puts a lot of pressure on me and I get nothing more from it than I would watching the recorded meeting.

The last Likert-scale question (Q11) asked participants if they watch the session's recording if they were not able to attend. Surprisingly, a significant majority $(89 \%, \mathrm{n}=39)$ expressed that they Strongly Agree or Agree with this statement, which is confirmed by comments like the following:

I do go back into blackboard and view the recording session and review what was discussed and most of the time most of the questions I ask are successfully answered in the recording. 
Having a recorded meeting is in many ways better because it allows the student to go back and forth to relisten for clarification. I prefer to watch a recording or read an assignment and, if I need more, I can contact the professor directly for additional information.

Although the majority were in favor of watching the recorded sessions, 4 participants $(9 \%)$ responded Disagree. There were interesting comments indicating that participants partially watch the sessions or do not benefit from the recordings:

I find I rarely go back and watch the entirety of the recorded video. I will skim through it until I reach parts that are relevant to my questions.

I don't like the idea that there may be information given in these sessions that would be greatly helpful to mebut, that I never get because the information is only given in the sessions.

\section{Results of Open-Ended Question}

In order to elaborate on their preferences, participants were asked to respond to an open-ended question. They were asked if they prefer fully asynchronous classes or classes with optional synchronous sessions and why. Responses provided additional insights regarding the asynchronous and synchronous sessions, as well as ideas to improve them. A very common observation involved the synchronous sessions' length and the use of time. As noted in the following comments:

The thing I would change with the synchronous sessions, is to cut the time down make them shorter than having an hour and a half to two hour sessions, especially late in the evenings.

I would prefer an option where the professor explains whatever topic they need to explain-frankly, with no interaction from the class. Simply a 30-minute lecture. Once the class becomes involved, you then have comments and questions that may or may not be helpful to all and this takes up session time that the professor may or may not have built in.

Sometimes the time is an issue, as students may not get equal time of participation/presentation due to one student taking more time than another. So I'd remind the students to be more respectful of the allowed time.

Some other participants reported being enrolled in online courses because of flexibility, which allows them to work at their own pace without the need to stop their other activities to attend classes. However, a couple of participants expressed the desire to attend, suggesting class reschedule to weekends.

On the other hand, since instructors have a 24-hour response time frame, participants indicated being satisfied communicating with them via email, and suggested increasing communication with classmates, noting:

...but with an email straight away from the instructor within the same/next day, that is was makes the online course feel like a traditional classroom.

I would like to see a forum/blog where the students can easily communicate with one another. The forum we have is great, but I would like one that is run by the students.

In addition to their perceptions of synchronous sessions and asynchronous courses, some more interesting comments arose from the open-ended questions for improvement. Presented below is a representative sample of their suggestions:

I would still prefer that the times of the voluntary sessions be made available at the time of registration. It would be much easier to plan for weekly sessions if we knew when they were in advance, rather than waiting to find out by reading the syllabus on the first day of class. 
If I were teaching an online course with synchronous sessions, I would only host the sessions to introduce project details. If there were 3 projects in the class, I would only have 3 sessions. ... I think participation would increase if you had fewer sessions per semester.

Whether or not the online course has synchronous sessions, I believe everything that is worth knowing should be available outside of the sessions.

If I were teaching a fully online course with synchronous sessions, I might offer extra credit to people who attend the live session and participate in the class. This could potentially increase involvement from people who are hesitant to attend. A rubric could be designed for extra credit based off of genuine participation.

\section{DISCUSSION}

This study sought to determine the preferences of graduate online students enrolled in Educational Technology courses regarding the delivery modes of their online courses. As argued by Giesbers, Rienties, Tempelaar, and Gijselaers (2014), a combination of synchronous and asynchronous communication enhances learner engagement and development. The previous statement is confirmed in this study, since it was found that students prefer a combination of asynchronous and synchronous components in the course. The majority of the students enrolled in these online courses, prefer including synchronous sessions, finding them to be useful and increasing instructor presence and collaboration with classmates. However, if students were required to attend class sessions, it was noticeable the reluctance of having these sessions being mandatory due to lack of time to fulfill personal activities. This is somehow contradictory because students prefer courses with synchronous sessions, but, since they are not mandatory, students do not attend the sessions due to lack of time and other responsibilities.

Students who attend reported finding value in the immediate responses to their questions and the feedback provided to their progress in projects and assignments that synchronous sessions offer. Also, reminders, clarifications, and suggestions for improvement are important information they find when attending a synchronous session. When students are not able to attend, it was preferred by the majority to record the sessions and make them available for future reference. Although attending synchronous sessions in the course is not required, it is needed that the majority of students attend the session, ask questions, and share their progress in projects and assignments in order to create recordings where valuable feedback and comments are offered to the other students.

It was found that almost half of the graduate students in this study are in favor of having synchronous sessions on a more sporadic frequency, or only when they are needed. Since participants in this study are enrolled in project-based courses, students prefer having synchronous sessions with the instructor when they need to discuss a project or ask questions related to the project's deliverables. It seems from the results of this study, that if fewer sessions are offered, participation could increase and students who reported sporadically participation could attend more sessions in the future than if they were offered on a weekly basis. The length of the session and its content was also pointed out by participants. Students suggested short sessions, covering key points of the topic, where students' participation time is limited in order to offer everyone equal time of participation, without the need to extend the session. This point can be justified because of the hour the sessions are offered. Live sessions are usually offered on a weekday between 7 p.m. and 10 p.m., and family responsibilities, as well as tiredness, become an issue to extend the sessions.

Since time constraints and personal responsibilities are the main limitations for students to invest time in online learning (Clark, Strudler \& Grove, 2015), and based on the previous findings, it is recommended for designers and faculty teaching online courses with similar characteristics as the Educational Technology courses in this study, that:

- When designing online courses, consider making the synchronous sessions optional and record the sessions to make them available for those who were not able to attend.

- Since weekly course-related topics are addressed asynchronously in the discussion forums, offer synchronous meetings when relevant information needs to be discussed.

- Pre-record the content of the session (i. e., lectures, summary of key points of the topic, projects' suggestions and deliverables), and have students view at their own pace the recordings before meeting live, and leave a shorter synchronous session for students' questions and answers or presentations. This way, students will be 


\section{Issues in Information Systems}

Volume 18, Issue 4, pp. 124-134, 2017

able to watch a short recording with only the instructor's input, as well as a recording with questions and answers for further clarification.

- A summary of all the instructions, deliverables, recommendations, resources, and suggestions that are to be included in a synchronous session, must be available asynchronously on the course site, in order to benefit those who are not able to attend or watch the recordings.

These recommendations could improve the way students have access to the materials and information in the course, no matter if it is delivered synchronously or asynchronously. The findings are also valuable for the team of faculty members designing and teaching the Educational Technology courses in this study, because it is expected that, by implementing the previous recommendations, students' attendance and participation in synchronous sessions in online courses increases, as well as their performance when completing projects and assignments. Although students referred to be comfortable using email as a form of communication with the instructor, by having the instructor's recommendations recorded and available, students could benefit by reducing the time they need to wait for instructor's feedback or response to a question.

\section{SUMMARY}

The purpose of this study was to determine and analyze students' perceptions of the asynchronous and synchronous delivery modes of the online Educational Technology courses, in order to identify their preferences. Results indicate that graduate students in this study prefer short voluntary live sessions, offered less frequently, where key points are addressed by the instructor. Recordings of the synchronous sessions were also preferred by students, since, due to time constraints, they are not able to attend the synchronous meetings.

In the future, it would be useful to look at the GPA of students in these courses, in order to determine if attending the synchronous sessions, watching the recordings, or not attending the voluntary sessions have an impact on students' performance. Researchers are encouraged to explore students' perceptions of the delivery of online courses that possess different characteristics than the ones in the Educational Technology courses in this study. Instruction and content materials in online higher education courses are delivered in different ways, and the characteristics of each course, impact students' perceptions and performance. Some factors influencing perceptions of synchronous sessions that could be further explored and analyzed include the level of the course (undergraduate or graduate), if synchronous sessions are mandatory or voluntary, the length of the live session, the hour it is held, the frequency that sessions are offered, the content that is reviewed in the session, and if a recording is available for future reference. Also, it is convenient to analyze perceptions in not project-based online courses which offer synchronous sessions. For instance, in lecture-based online courses, where resources are mainly offered through the live session, would it be beneficial for students to pre-record the lecture and use synchronous sessions for discussions, and questions and answers, in order to shorten the session?

Research in the delivery of online courses in order to increase students' participation and performance is still needed. This study ought to offer recommendations for faculty teaching online courses based on the findings when analyzing specific courses in Educational Technology.

\section{REFERENCES}

Branon, R. F. \& Essex, C. (2001). Synchronous and asynchronous communication tools in distance education: A survey of instructors. TechTrends 45(1), pp. 36-42.

Burns, S., Cunningham, J. \& Foran-Mulcahy, K. (2014). Asynchronous online instruction: Creative collaboration for virtual student support. The CEA Critic, 76(1), pp. 114-131. doi: 10.1353/cea.2014.0007

Clark, C., Strudler, N. B. \& Grove, K. J. (2015). Comparing asynchronous and synchronous video versus text based discussions in an online teacher education course. Online Learning Journal, 19(3). doi: 10.24059/olj.v19i3.668 
Giesbers, B., Rienties, B., Tempelaar, D. \& Gijselaers, W. (2014). A dynamic analysis of the interplay between asynchronous and synchronous communication in online learning: The impact of motivation. Journal of Computer Assisted Learning, 30, pp. 30-50. doi: 10.1111/jcal.12020

Hrastinski, S. (2008a). Asynchronous and synchronous e-learning. EDUCAUSE Quarterly, 31(4), pp. 51-55.

Hrastinski, S. (2008b). The potential of synchronous communication to enhance participation in online discussions: A case study of two e-learning courses. Information and Management, 31, pp. 499-506.

Huang, X. \& Hsiao, E. (2012). Synchronous and asynchronous communication in an online environment: Faculty experiences and perceptions. The Quarterly Review of Distance Education, 13(1), pp. 15-30.

Martin, F. \& Parker, M. A. (2014). Use of virtual classrooms: Why, who, and how? MERLOT Journal of Online Learning and Teaching, 10(2), pp. 192-210.

Oztok, M., Zingaro, D., Brett, C. \& Hewitt, J. (2013). Exploring asynchronous and synchronous tool use in online courses. Computers \& Education, 60(1), pp. 87-94.

Willging, P. \& Johnson, S. (2009). Factors that influence students' decision to dropout of online courses. Journal of Asynchronous Learning Networks, 13(3), pp. 115-127. 